Biologie du Commissariat à L'Energie Atomique located at the Station Zoologique, Villefranche-sur-Mer, France. Born in Mutzig in Alsace in 1922, he was educated at the Ecole Normale Supérieure in Paris, and worked at Saclay before going to Villefranche in 1964.

Early attempts to measure teleostean osmoregulation with radioisotopes had been made in the fifties, and revived by Motais in 1961. Maetz with Motais in 1965 discovered that in sea-water the gill was the major site of sodium exchange, and that up to $100 \%$ of the internal sodium could be exchanged each hour. Maetz was quick to realise the importance of techniques which allowed both influx and efflux of ions across the gill to be measured while the salt balance of the animal was not disturbed. He refined and automated these techniques with the effect that a constant stream of papers has flowed from his laboratory in which a variety of perturbations (ionic strength, temperature, hormones) were employed and their effects on branchial fluxes described. He was particularly interested in problems of adaptation in euryhaline fishes and while he stressed the difficulty of obtaining exact thermodynamic data in whole animals he enjoyed building models to describe the data. These wore intended as a challenge to others to do experiments designed to test the models.

It is in no small part due to his stimulus that there is a lively interest in branchial transport today. While there is now general agreement about the active transport of chloride in the seawater gill, the mechanism of $\mathrm{Na}-\mathrm{K}$ exchange is more controversial. Whether exchange proceeds by an active mechanism or is a result of potential changes accompanying alterations in composition of external medium is still a matter of dispute. Although Maetz with Campanini in 1966 were the first to show the change in gill potential which followed when eels were transferred from sea water to fresh water Maetz initially favoured an active mechanism. More recent observations suggest that $\mathrm{Na} / \mathrm{K}$ exchanges are diffusive in nature, yet awkward observations remain to indicate that some component of the exchange is potential insensitive. It is a tragedy he will not be able to resolve this matter after contributing so much of the information on which the discussion is based.

The impact of the mass of phenomenological data, collected for many diflerent species, which has come from his efforts has perhaps not yet been realised. Its importance to ecology and relevance with regard to the changing environment of the seas and estuaries may be considerable.
More recently he turned to simpler systems such as the perfused gill, work already started with Rankin, and to biochemical and morphological studies of chloride cells. It is to be hoped others will continue to explore his ideas in these areas.

Jean Maetz was a man of great charm with an infectious enthusiasm for research. Many of his former students now hold positions in research institutions and his laboratory was never without visiting scientists, who came from all over the world. A visit to his laboratory was a commitment to do experiments, and often at the end of the day to enjoy the hospitality and friendship offered by his whole family. $\mathrm{He}$ is survived by his wife, Betty, and two daughters.

A. W. Cuthbert

\section{Louis Fieser}

Louis Frederick Fieser was an exemplar of excellence promoted and sustained by Harvard University. Born in Columbus, Ohio, on April 7, 1899, he completed his Ph.D. degree under J. B. Conant at Harvard in 1924. After five years on the staff of Bryn Mawr College (where he discovered his aptitude for teaching) he returned to the Harvard chemistry department in 1930 , becoming Sheldon Emery Professor of Organic Chemistry (1939-1968) and Professor Emeritus from 1968 until his death on July 25, 1977.

Among the honours conferred on Fieser were Fellowship of the National Academy of Sciences (1940), and the D.Pharm. honoris causa of the University of Paris (1953). From the American Chemical Society he received the Wm. H. Nichols Medal (1963) and the Award in Chemical Education (1967).

Fieser's abounding enthusiasm for investigative organic chemistry was rooted in his own experimental work, which he continued throughout his career. His attachment to bench work is well portrayed in the photograph that accompanied a biographical sketch by Dr Hans Heymann in the Journal of Organic Chemistry of June 1965-an issue composed of numerous papers dedicated to Fieser on the occasion of his 66th birthday, by authors from many countries who had been students or post-doctoral workers in the Converse Memorial Laboratory.

Early research by Fieser stimulated developments in several fields which have remained important. In 1939, he established the structure of Vitamin $\mathrm{K}_{1}$ by a synthesis of characteristic practicality, isolating the natural vitamin from alfalfa extract for comparison. Fieser had earlier devised syntheses of methylcholanthrene and other carcinogenic hydrocarbons, and his varied interests led him to compile (with Mary
Fieser) his books on Natural Products Related To Phenanthrene (1936, 1937) in which the developing (and confused) chemistry of the steroids was skilfully elucidated and critically reviewed. In the 1937 volume, Fieser introduced the $\alpha / \beta$ nomenclature now universally employed to designate hydroxy and other substituent configurations in the steroid nucleus. The 3 rd edition appeared in 1949 , benefiting from (and contributing to) the burgeoning of steroid research that accompanied the discovery of the therapeutic value of cortisone.

The ensuing decade saw remarkable advances in steroid chemistry and biochemistry which had an impact in much wider fields. Observations by Fieser on the stereochemistry of steroid reactions were among the stimuli that led D. H. R. Barton (while a Visiting Lecturer at Harvard) to develop the principles of conformational analysis. In addition to participating in many aspects of research on steroids, Fieser found time to compile-again with his wife as co-author --the masterly 4 th edition of the original book, necessarily retitled Steroids (1959) because the wealth of new information compelled the exclusion of other material.

Fieser's insight in selecting significant research topics is exemplified by his early work on benzo $[\alpha]$ pyrene, the carcinogenic action of which has only recently been clarified in structural terms. Another of his interests concerned the possibility that carcinogenicity might arise from minor sterols occurring as companions of cholesterol: he isolated a number of such minor components from commercial cholesterol. Although no carcinogenic sterols (with the exception of cholesterol $\alpha$-oxide) appear to be known, recent work has indicated that certain compounds such as 25-hydroxycholesterol may have significant biochemical effects.

Fieser himself considered that success in teaching was his major accomplishment. At Harvard, his attractive informality as a lecturer won him the students' acceptance of a rigorous introductory course in organic chemistry, generally regarded as 'tough. hut well worth it' by the participantswho numbered more than 8,000 during the 30 years of the course. Experimental skill was assiduously inculcated, as in the annual Martius Yellow prize competition for the practical class, in which 'Louie' frequently took part.

Fieser's earliest texthook, Experiments in Organic Chemistry (1935), and its painstakingly revised successors, conveyed up-to-date techniques to students world-wide: the colour pictures showing how to construct a hot-plate from a can labelled 'Gorton's Cod Cakes' impressed even those readers 
who were unacquainted with those comestibles.

The 1957 edition of Experiments included an informative review of some 320 reagents: from this modest chapter, Mary and Louis Fieser were to develop their monumental series of handbooks entitled Reagents for Organic Synthesis-five volumes comprising more than 4,000 pages of invaluable information and references for research workers.

During the Second World War, Fieser's attention was diverted to investigations on antimalarial drugs of naphthoquinone type. He also played a leading role in the development of incendiary preparations, including napalm. It is clear from his personal account of this work, in the book The Scientific Method that while Fieser relished this challenge to the skill of his research team, he was impatient to resume his own research at the earliest opportunity.

Meanwhile, his enforced travels on war service provided some spare hours in which he began (in collaboration with Mary) the first of a series of sparkling and scholarly textbooks on organic chemistry, in which the excitement of discovery was conveyed in a lively, lucid and gracefully literate style. These works deservedly achieved great international success, both in the original and in translations. The first Japanese edition of the Textbook of Organic Chemistry appeared in 1952 just as peace was formally resumed between the U.S.A. and Japan: its frontispiece portrayed the Fiesers' Siamese cat accompanied by one of Japanese breed, symbolising the authors' hope that their work would promote reconciliation.

In later years, the Fiesers produced two further books for advanced students, Advanced Organic Chemistry (1961) and Topics in Organic Chemistry (1963) together with a Style Guide for Chemists and other works. Fieser also promoted the study of stereochemistry by means of his inexpensive molecular models based on those of Dreiding.

It was typical of Fieser's determination that after undergoing surgery for a lung tumour he became a campaigner on the risks of smoking, in addition to pursuing his customary literary work. The elegance of the latter matched that of his Siamese cats, but in his perseverance Fieser was more appropriately described by his mottoes, which were Omnia possum and Labor omnia vincit.

The human warmth implicit in Fieser's books prompted affection for the author in many readers who had no opportunity of direct contact with him. Friends and disciples known and unknown will salute the memory of a creative and courageous chemist, and offer their condolences to Mary, his wife and scientific partner throughout his career.

C. J. W. Brooks

\section{Sir Frederic Williams}

Professor Sir Frederic Williams, FRS, who died after a year-long illness on 11 August 1977 had held the Edward Stocks Massey Chair of ElectroTechnics at the University of Manchester since 1946; he was famed for his pioneer work on electronic circuitry and digital computers, and was perhaps less well known for his variablespeed induction motors and his new transmission system for a motor-car.

Frederic Calland Williams was born on 26 June 1911. He was educated at Stockport Grammar School, the University of Manchester (B.Sc. and Fairbairn Prize 1932, M.Sc. 1933, D.Sc. 1939) and Magdalen College, Oxford (D.Phil. 1936). He joined the staff of the Electro-Technics Department at Manchester in 1936, but left in 1939 to join the Scientific Civil Service at Bawdsey. During the war he worked on radar at TRE (Telecommunications Research Establishment; now the Royal Radar Establishment). It was at TRE that his inherent ability in circuitry became apparent. Those were the days of valves and he used them in unconventional ways to generate the waveforms required in the rapidly developing field of radar. There were circuits actively using all the electrodes of a pentode; diodes were employed for 'catching'; feedback (both positive and negative) was used. It is believed that Williams introduced the 'virtual earth' idea which so simplifies the analysis of negative feedback amplifiers. At TRE he also made contributions to servomechanisms.

When he became Professor at Manchester, all the war-time experience was incorporated in new courses which he gave to undergraduates (the whole staff attending, too). This experience also enabled him to start new research lines in his department. Most significantly, he brought to Manchester an idea for a digit store for a computer. There were computers in 1946, but they lacked storage. The Williams device stored binary digits as a charge pattern on the screen of a cathode ray tube. The pattern was scanned and read and continuously 'refreshed' by re-writing from the read-out. It was possible to inspect any point of the pattern at random; access time was thus shorter than in acoustic delay lines-a rival system of storage being developed elsewhere.

A complete prototype computing machine incorporating the Williams tube store was built in the laboratory at Manchester and a commercial version was produced by Ferranti Ltd., who installed about 20 computers in various establishments in this country and abroad. Early in the development of the second Manchester machine, Professor Williams' interest in computers waned and he took up other interests. However, he must surely be of that small company of men deserving the title of 'Father of the Computer.'

The new interest was induction machinery. The induction motor is essentially a constant-speed machine, although there are machines with two separate windings either of which can be excited to give a two-speed machine. Williams sought to make an induction motor whose speed could be continuously variable over a range and all of whose windings were used all the time. There was the disc motor derived from the linear induction motor; this was a flea-power machine which demonstrated the practicability of the idea, but it led to the spherical motor in which almost the whole surface of the rotor was in active use. A large motor of this type was made by Metropolitan-Vickers Electrical Company, but the machining of spherical surfaces proved difficult and this may be why no further machines were made.

There followed the 'log-motor' (a machine of amazing ingenuity), the phase-change motor (in which twothirds of the windings were supplied through variable phase changers), several machines with discrete speeds and an induction-excited alternator. $\mathrm{He}$ also produced slow high-torque motors using the direct pull between magnetised surfaces.

Whatever his interest at a particular time, Professor Williams spent practically all his time in the laboratory or the workshop. Administrative work was left as much as possible to others and the time spent at his desk was minimised. He was nearly always to be found, in a cloud of tobacco smoke, supervising the construction of a device or its testing.

He was awarded honorary doctorates from four Universities and was elected to Fellowship of the Royal Society in 1950. He received many medals and other awards. He was made a Knight Bachelor in the Birthday Honours in 1976. In his own University he was held in great respect and affection and he ran his Department with an easy authority; his staff pursued their own interests and under his guidance their individual abilities developed. More than 20 of his protégés are now Professors.

Sir Frederic is survived by Lady Williams, a son, a daughter and four grandsons. 